\title{
Diótima. Politica e potere non sono la stessa cosa*
}

\section{Mariateresa Muaraca**}

Elaborar esta resenha significou para mim me engajar no desafio de um processo de tradução que vai muito além da dimensão linguística, e que aceitei porque confio que "a tradução é política e teoricamente indispensável para forjar epistemologias e alianças políticas feministas" (Alvares, 2009:744). A complexidade do desafio se deve, sobretudo, à dificuldade de traduzir para um público brasileiro o pensamento do feminismo italiano da diferença, de que a reflexão do livro é expressão e que não tem difusão no Brasil. Portanto, faz-se necessário uma contextualização antes de entrar propriamente na resenha.

Os centros nevrálgicos de elaboração do feminismo da diferença italiano são Diótima ${ }^{1}$, uma Comunidade Filosófica Feminina, nascida na Universidade de Verona em 1983, e a Livraria das Mulheres de Milão ${ }^{2}$, autora do texto fundante do feminismo da diferença na Itália Non credere di avere dei diritti. La generazione della libertà femminile nell'idea e nelle vicende di un gruppo di donne [Não creia de ter direitos. A geração da liberdade feminina na ideia e nas vivências de um grupo de mulheres] de 1987.

\footnotetext{
* Resenha de Diótima. Politica e potere non sono la stessa cosa. Napoli: Liguori, 2009. Recebida para publicação em 16 de outubro de 2013, aceita em 10 de fevereiro de 2015.

** Doutoranda em co-tutela na Universidade de Verona (Programa de Doutorado em Ciências da Educação e da Formação Continua), Itália, e a Universidade Federal de Santa Catarina (Programa de Pós-Graduação Interdisciplinar em Ciências Humanas), Florianópolis, SC, Brasil. mariateresa.muraca@univr.it

1 www.diotimafilosofe.it.

2 www.libreriadelledonne.it.
} 
A partir da crítica do sujeito neutro supostamente universal da filosofia moderno-ocidental e em contraposição ao feminismo da igualdade, o feminismo da diferença elaborado por Diótima coloca a diferença entre os sexos como uma diferença fundamental e assimétrica, ao mesmo tempo em que recusa uma concepção a-histórica e essencialista dessa diferença, que a identifique com a divisão sexual dos papeis sociais. Nesse sentido, Diótima aposta em um sentido livre da diferença feminina que se configura como radicalmente transformadora porque questiona a ordem simbólica e social marcada pela dominação do sujeito masculino. Os pontos de referência fundamentais para o feminismo da diferença italiano são o pensamento de Luce Irigaray e o debate teórico e político do movimento das mulheres. Outras autoras significativas no trabalho filosófico desenvolvido por Diótima são Simone Weil, Carla Lonzi, Maria Zambrano, Hannah Arendt, Virginia Woolf, Julia Kristeva, Adrienne Rich, Clarice Lispector, Etty Hillesum, etc. Algumas das reflexões mais originais de Diótima são relativas à ordem simbólica, ao conceito de autoridade, às práticas políticas do movimento das mulheres $e$ à relação entre poder e política, tratada no livro Potere e politica non sono la stessa cosa [Poder e política não são a mesma coisa], o $11^{\circ}$ livro de Diótima, que é objeto desta resenha.

As autoras dos sete ensaios em que se articula o livro desenvolvem uma ideia comum: entre poder e política há uma relação de profunda proximidade, mas também de exclusão recíproca, de modo que a confusão com que eles são tratados despotencializa a política. Trata-se de uma reflexão que pode suscitar reações de rechaço, por apresentar uma visão crítica do poder que leva até a recusa da busca do poder como caminho de libertação válido para as mulheres, mas que considero relevante justamente por sua força provocatória e desconstrutiva, que pode funcionar como antídoto a uma confiança ingênua na reivindicação de maior poder como solução ao problema da exclusão secular das mulheres. Em seguida, entrarei nos detalhes da argumentação de cada autora, com o objetivo de esboçar os 
elementos centrais do pensamento sobre o tema da relação entre poder e política da Comunidade Diótima no seu conjunto.

Segundo Diana Sartori o posicionamento frente ao poder é uma questão central da política e da reflexão dos feminismos. Ao redor dessa questão se desenvolve um conflito simbólico e político sobre o próprio sentido do feminismo. Ou seja, se ele deve ser lido como uma reivindicação de poder, como um processo de emancipação que, em nome do universalismo, estenda às mulheres os mesmos direitos de que gozam os homens; ou se, pelo contrário, o feminismo tenha que ser entendido como um rechaço radical ao modelo de libertação como conquista do poder $e$ à ideia de política como exercício e distribuição do poder. De toda forma, segundo Sartori, pode-se dizer que as feministas têm uma postura crítica a respeito do poder e concordam em colocar o poder como problema.

A atual crise da política italiana, profundamente ridicularizada e menosprezada, estimulou as reflexões de Politica e potere non sono la stessa cosa. Fulvia Bandoli, feminista e mulher comprometida em movimentos sociais, partidos de esquerda $e$ associações da sociedade civil, descreve essa crise como a crise do sistema dos partidos, que chegaram a um nível tão grande de corrupção e contradição que se tornou impossível reformá-los internamente. A autora sublinha a necessidade de reconstruir a política em outros lugares, inventando novas práticas, sem, com isso, deixar de entrar nos territórios mais contraditórios e mais difíceis: os do poder. Nesse sentido, Antonella Cunico explora as formas de uma política em muitos aspectos inédita, produzindo pensamento a partir da sua militância no grupo de mulheres que se articulou no interior do movimento No dal Molin ${ }^{3}$. A autora defende a necessidade de se manter fiel simultaneamente à ação $e$ à reflexão, não se tornando instrumento daquilo que faz e não caindo na confusão de não saber se a ação corresponde realmente ao que profundamente se deseja.

3 Trata-se de um movimento social nascido em Vicenza (Itália), em 2006, para opor-se à construção de uma base militar dos EEUU no território da cidade. www.nodalmolin.it. 
A atual crise, entretanto, é uma crise não apenas da política, mas também dos lugares políticos. Por exemplo, a escola - onde Giannina Longobardi focaliza sua atenção - nos últimos quinze anos foi golpeada por contínuas reformas e leis que privilegiaram a privatização e a padronização do ensino, que foi submetido a lógicas e processos uniformizados, que não respeitam a especificidade dos contextos e das pessoas, empobrecem as relações político-educativas e criam ovelhas de rebanho ao invés de cidadãos.

Sartori propõe considerar a política e o poder como polos de um continuum e, baseando-se nas reflexões feministas - nem sempre concordantes entre si - oferece alguns indícios para que seja esboçada uma fenomenologia da relação entre eles. O poder se apresenta como um meio para alcançar outras coisas: a felicidade, a justiça, o bem comum, a preservação da vida e do mundo. Contudo, frequentemente, o meio se torna fim, pois o poder, em razão da sua natureza, aspira à sua conservação. É o caso, segundo Luisa Muraro, dos revolucionários que acreditavam que, para realizar o socialismo, fosse indispensável tomar o poder, sendo que, no interior de sua própria lógica, acabaram se tornando meras ferramentas para o alcance de finalidades alheias. Assim, a política não pode usar o poder para seus objetivos como se fosse um meio, ao mesmo tempo em que não é possível subtrair-se completamente à sua pressão. $\mathrm{O}$ poder se fundamenta na razão instrumental e, por isso, supõe um mundo previsível, que pode ser controlado. Ao contrário, a política é, nos termos de Arendt, iniciadora de algo novo, tendendo a abrir a realidade para possibilidades inéditas e rompendo com a ordem dominante. Assim a política se torna infinita e ontologicamente criadora. $\mathrm{O}$ conflito se configura também de modos diferentes na perspectiva do poder e na perspectiva da política. Por um lado, o poder tende à eliminação do outro e à redução da pluralidade a Um, por meio de alianças nem sempre muito claras. Por outro lado, a política é capaz de mediação, sabe lidar com diferenças conflituosas e se abre à novidade, à mudança, ao imprevisto e, por isso, é também mais frágil. A tradição tem ligado o poder ao corpo masculino, ele 
é rodeado pelo imaginário sexual masculino ao ponto de não ser fácil entender se o poder é um substituto do sexo ou se o sexo é imaginado como poder. O fato é que, historicamente, o espaço masculino do exercício do poder foi preservado ao preço da exclusão das atividades consideradas pré-políticas ou antipolíticas, as atividades de cuidado com a vida material, destinadas às mulheres. Entretanto, trata-se de uma exclusão-inclusão: pois o que é marginalizado e deslegitimado é de toda forma necessário para a manutenção da ordem dominante. Nesse sentido, o poder pressupõe um sujeito que se imagina $e$ age como independente $e$ racional, que tem relações de voluntariedade e contratuais com os outros e que se identifica com a lei do $\mathrm{pai}^{4}$ por meio das hierarquias de comando e obediência. Trata-se do sujeito da modernidade, que entende a sua liberdade a partir da noção de "autonomia" ou "autodeterminação", de forma a desconsiderar o âmbito relacional. A política, ao invés disso, é guiada por uma visão intersubjetiva e relacional, reconhecendo a necessária dependência da condição terrestre e plural; o seu ideal é o sujeito relacional. Assim, o deslocamento promovido pela política questiona o caráter ilusório da autonomia em favor de um reconhecimento da interdependência.

Para esclarecer a relação entre política e poder, Chiara Zamboni utiliza uma imagem elaborada por Maria-Milagros Rivera Garretas no seu Donne in relazione. La rivoluzione del femminismo [Mulheres em relação. A revolução do feminismo]

\section{[...] é como jogar xadrez e damas no mesmo tabuleiro. A característica do jogo de damas é que cada peça se move livremente no tabuleiro, enquanto no xadrez cada peão tem movimentos predefinidos. [...] A lógica de jogar xadrez é de interpretar cada ação, também das peças de damas, como se fosse o movimento de um Cavalo, de um Peão ou da}

\footnotetext{
4 Segundo Sartori, a luta pelo poder expressa uma dinâmica edípica interna à ordem masculina: os filhos matam o pai pra instituir em nome dele uma ordem destinada a ser de novo revolucionada por outros filhos parricidas e assim por diante.
} 
Rainha. Ou seja, movimentos ligados a uma lógica de poder, onde cada um tem uma posição na hierarquia $e$ possibilidades de ação definidas naquela posição [...] uma dificuldade ainda maior está no fato de que também as peças de damas frequentemente [...] interpretam aqueles que têm diante de si apenas como jogadores de xadrez [...] eu mesma tenho dificuldade em ver que - nas hierarquias de poder - as mulheres $e$ os homens nunca aderem completamente àquela identidade que fixa os papéis que podem desenvolver. Em geral podemos apoiar-nos sobre esta possibilidade de ser também outra coisa para convidálos a jogar damas. Nesse sentido, temos maiores possibilidades de ganhar quando criamos as condições que permitem a um peão ou a um rei moverem-se como uma peça de damas, isto é, livremente, fora da lógica prevista pelo poder. Os convidamos a jogar o jogo da política (p.121-122, tradução minha). ${ }^{5}$

$\mathrm{O}$ antídoto que Muraro sugere "à confusão do poder que devora a política" é a independência simbólica do poder.

Para abrir o mundo a uma transformação de economia simbólica é essencial não se encarcerar as relações de força com aberturas de crédito para as autoridades constituídas. Também o

${ }^{5}$ No texto original "È come se si giocasse a scacchi e a dama sulla stessa scacchiera. La caratteristica del gioco della dama è che ogni pedina si muove liberamente sulla scacchiera, mentre nel gioco degli scacchi ogni figura ha delle mosse predefinite [...] La logica di chi gioca a scacchi è di interpretare ogni azione anche della dama come se fosse la mossa di un Cavallo, o di un Pedone o di una Regina. Cioè mosse legate alla logica di potere, dove ognuno ha una certa posizione gerarchica e possibilità di azione definita da quella posizione [...] Non solo, ma una difficoltà ancora maggiore sta nel fatto che anche le dame di frequente - e lo vedo a partire da me - interpretano coloro che hanno di fronte solo come giocatori di scacchi [...] io stessa ho difficoltà a vedere che - nelle gerarchie di potere - le singole donne e uomini non aderiscono mai completamente a quellidentità fissa che i ruoli portano a seguire. In genere possiamo fare leva su questo loro essere anche altro, per invitarli a giocare a dama. Allora abbiamo possibilità di vincere quanto più creiamo le condizioni perché un Pedone e un Re si muovano come una doma, cioè liberamente, fuori dalla logica prevista di potere. Li invitiamo a giocare il gioco della politica" (Zamboni, em Diótima, 2009:121-122). 
antagonismo é uma abertura de crédito que nos vincula e nos faz entrar no campo gravitacional do poder [...], é preciso se subtrair ao poder, eliminando cada obrigação e cada expectativa para com ele (p.12, tradução minha, cursivo meu). ${ }^{6}$

Segundo Zamboni, Foucault esclareceu bem que a realidade é estruturada pelas relações de poder e que ele pertence à ordem da necessidade, mas sua limitação foi não considerar a política.

Para se subtrair ao poder Foucault tem confiado apenas no conceito de resistência local, que continua sendo delineada no dispositivo do poder e assim é complementar ao simbólico dominante [...] se se toma o poder como significante único para ler $e$ interpretar a realidade, joga-se o seu jogo e se acrescenta a sua força mais do que ele tem de fato. Fica-se aprisionado na lógica do suspeito até considerar a si mesmo como instrumento $e$ artífice do poder, com sentidos de culpa e ressentimento (p.119120 , tradução minha, cursivo meu). ${ }^{7}$

Em outras palavras, o domínio, para se instaurar e para durar, precisa do crédito dos dominados. Trata-se de algo que as mulheres aprenderam por meio da prática política da autoconsciência, isto é, entenderam que eram cúmplices do patriarcado e que esse sistema de poder perderia força se elas começassem deixar de sustentá-lo dando-lhe crédito.

${ }^{6}$ No texto original "Per aprire il mondo a un cambio di economia simbolica, è essenziale non incatenarsi al piano dei rapporti di forza con aperture di credito nei confronti delle autorità costituite. Anche il mettersi contro è un'apertura di credito che vincola e ci fa entrare nel campo di gravitazione del potere [...] il significato che io ho intuito [...] è la sottrazione di sé alla sua presa avendo eliminato ogni obbligo ed ogni aspettativa nei suoi confronti" (Muraro, em Diótima, 2009:12).

7 No texto original "Per sottrarsi al potere si è affidato solo al concetto di resistenza locale, che però rimane disegnata dal dispositivo di potere e dunque complementare al simbolico dominante [...] Se si prende il potere come significante unico per leggere e interpretare la realtà, allora si fa il gioco del potere $e$ se ne aumenta la forza, più di quanto esso ne possiede di fatto. Si rimane intrappolati dalla logica del sospetto, che fa considerare anche noi stessi come strumento del potere, e dunque suoi artefici, con sensi di colpa e risentimento" (Zamboni, em Diótima, 2009:119-120). 
Nesse sentido, deve ser compreendida a radical proposta de Annarosa Buttarelli, que, no ensaio que encerra o livro, declara que é necessário "despedir-se definitivamente do crédito que muitas de nós damos às instituições e aos aparatos da democracia representativa" (p.130, tradução minha, cursivo no texto). ${ }^{8}$ Seguindo o pensamento de Nicole Loraux e Valeria Andò, Buttarelli demonstra que há uma radical inconciliabilidade entre as mulheres $e$ a democracia representativa. $O$ princípio da representação implica a redução da multiplicidade a Um, quer dizer, é acompanhada da obsessão de alguém em substituir os outros e se tornar dono da vontade deles, em contradição com a consciência de que cada ser humano está sempre envolvido nas relações - uma consciência que pertence mais às mulheres que aos homens, pois cada mulher é parte de uma genealogia, que inclui pelo menos três pessoas: ela, a mãe e a mãe da mãe. Segundo ela, as mulheres não gostam de comandar, mas sim, de dominar, o que no seu sentido originário significa se envolver completamente nas relações com os outros e com as coisas. Ela pensa ser possível conciliar a democracia e a autoridade feminina. Não se pode dar conta em poucas linhas da complexa reflexão que o feminismo italiano da diferença dedicou ao tema da autoridade $^{9}$, sobre o que, aliás, se concentra a discussão de Cristina Faccincani ao expor os perigos da metamorfose da autoridade em poder na relação psicanalítica. Será suficiente evidenciar que o rechaço do poder no feminismo italiano da diferença não se traduz simplesmente na cegueira sobre as assimetrias que existem entre as mulheres, pois a diferença é uma categoria que envolve não apenas as relações entre mulheres $e$ homens, mas também as relações entre as próprias mulheres. Nesse sentido, a autoridade, diversamente do poder, articula-se

\footnotetext{
8 No texto original "congedarsi definitivamente dal credito dato da molte di noi alle istituzioni e agli apparati che definiscono la democrazia della rappresentanza" (Buttarelli, em Diótima, 2008:130; cursivo no texto).

9 Para um aprofundamento faz-se referência ao $4^{\circ}$ de Diotima Oltre l'uguaglianza. Le radici femminili dell'autorità [Para além da igualdade. As raízes femininas da autoridade]
} 
com o exercício da liberdade; não se cristaliza em uma pessoa, mas circula na relação. A origem etimológica da autoridade vem do verbo augere, que significa aumentar, fazer, crescer. Portanto, na elaboração de Diótima, existe uma profunda ligação entre autoridade e desejo: pois se reconhece autoridade a quem movimenta situações e pessoas na direção desejada da realidade.

Questionar o conceito de poder como elemento de continuidade do pensamento masculino implica problematizar a ênfase dada à ausência sistemática das mulheres dos lugares de poder e de visibilidade. Interrogamos a ausência. $\mathrm{O}$ que ela nos diz? Talvez nos mostre algo mais de uma opressão que vem se desenvolvendo ao longo de séculos. Talvez nos revele uma resistência que visa não confirmar $e$ a reproduzir o mundo tal como é; um potencial revolucionário que, ao invés de focar-se na luta para a inclusão das oprimidas no sistema tal como é, abre possibilidades inéditas de transformação radical da realidade.

\section{Referências bibliográficas}

Alvarez, Sonia E. Construindo uma política feminista translocal da tradução. Revista de estudos feministas. Florianópolis, Sept./Dec. 2009, pp.743-753.

DıÓTIMA. Oltre l'uguaglianza le radici femminili dell'autorità. Napoli, Liguori, 1995.

LonZI, Carla. Sputiamo su Hegel e altri scritti. Milano, et al, 2010. 